\title{
Alkaloid extracts from Combretum zeyheri inhibit the growth of Mycobacterium smegmatis
}

Tafadzwa Nyambuya ${ }^{1}$, Ruvimbo Mautsa ${ }^{2}$ and Stanley Mukanganyama ${ }^{2^{*}}$

\begin{abstract}
Background: Current tuberculosis regimens have failed to combat the issue of drug resistance and ethno medicines may represent a possible source of antimycobacterial agents. Combretum species are well known in African traditional medicines and used for various ailments including pneumonia, venereal diseases like syphilis, mental problems, relief of sore throats and colds, fever, and chest coughs associated with tuberculosis. Alkaloids function as either hydrogen-acceptor or hydrogen-donor in hydrogen bonding critical for the interaction between targets thus, potentiating effects of curative agents on diseases. Alkaloid extracts from leaves of Combretum zeyheri, Combretum platypetalum, Combretum molle and Combretum apiculatum, were assessed for antimycobacterial activity to establish rationale for their use in traditional medicines for various ailments including pneumonia, relief of sore throats and colds, fever, and chest coughs associated with tuberculosis.

Methods: Alkaloids were extracted from the leaves of Combretum zeyheri, Combretum platypetalum, Combretum molle and Combretum apiculatum. The broth microdilution method was used for the screening of growth inhibitory activity. The standard drug rifampicin was used as the positive control. Alkaloid extracts from the most potent plant species, Combretum zeyheri were further investigated for time-kill dependency effects on drug transport in Mycobacterium smegmatis.

Results: Using the broth microdilution susceptibility method, C. zeyheri alkaloid extract, was found to have the most antimycobacterial effects with an MIC value of $125 \mu \mathrm{g} / \mathrm{ml}$ whilst MICs for C. molle and C. platypetalum were above $1000 \mu \mathrm{g} / \mathrm{ml}$. An MBC value of $250 \mu \mathrm{g} / \mathrm{ml}$ was observed with alkaloid extracts from Combretum zeyheri whilst the remaining three Combretum species showed no bactericidal activity. It was also shown that C. zeyheri had potential efflux pump inhibitory activity. Determination of the time-kill kinetics of extracts from C. zeyheri showed not only a concentration-dependent activity but time-dependent bactericidal effect as well.
\end{abstract}

Conclusions: Alkaloid extracts from the leaves of C. zeyheri have potential as a source of lead compounds that may be developed further into antimycobacterial compounds. The mechanism of action of may be due to inhibition of transport across the cell membrane. Further work needs to be done to isolate the active components in these extracts.

Keywords: Combretum species, Mycobacterium smegmatis, Drug efflux, Drug susceptibility test, Alkaloid extracts

\footnotetext{
* Correspondence: smukanganyama@medic.uz.ac.zw;

smukanganyama01@gmail.com

${ }^{2}$ Department of Biochemistry, University of Zimbabwe, P.O. Box MP 167, Mt

Pleasant, Harare, Zimbabwe

Full list of author information is available at the end of the article
}

(c) The Author(s). 2017 Open Access This article is distributed under the terms of the Creative Commons Attribution 4.0 International License (http://creativecommons.org/licenses/by/4.0/, which permits unrestricted use, distribution, and reproduction in any medium, provided you give appropriate credit to the original author(s) and the source, provide a link to the Creative Commons license, and indicate if changes were made. The Creative Commons Public Domain Dedication waiver (http://creativecommons.org/publicdomain/zero/1.0/) applies to the data made available in this article, unless otherwise stated. 


\section{Background}

Tuberculosis (TB) is a bacterial infection caused by a bacterium called Mycobacterium tuberculosis. Unique about mycobacterium, is the cell wall structure which contains mycolic acids intercalated to peptidoglycan - associated polysaccharides [1]. There are various strains of mycobacterium and transmission is through the lymph nodes and the blood stream to any organ of the body but mainly affects the lungs causing pulmonary tuberculosis. It may disseminate to other body parts causing extra-pulmonary tuberculosis [2]. The bacterium generally exists in its inactive form and only a few people infected will develop the active form of the disease [3]. Approximately 8 million TB cases emerge every year whilst at most 5000 people die from the disease everyday worldwide [4].

In most developing countries there is a relationship between HIV/AIDS and tuberculosis. According to the World Health Organisation (WHO) one-third of patients living with HIV are infected with TB [5]. Patients living with HIV are 35 times more likely to become infected with TB than people without HIV [6]. The treatment regimens consist of a combination of 5 first line medicines; rifampicin, isoniazid, pyrazinamide, ethambutol and streptomycin (HREZS) [7]. The initial intensive phase of includes rifampicin, isoniazid, pyrazinamide and, ethambutol daily for 2 months and a continuation phase of rifampicin and isoniazid for a further 4 months, either daily or 3 times a week [8]. Resistance of mycobacterium to conventional drugs is mainly due to inadequate exposure of the TB causing organism to anti-tuberculosis drugs [9]. The ability of mycobacterium strains to increase activity of their efflux pumps preventing drugs from reaching intended targets is amongst the major reasons of multi-drug resistant tuberculosis (MDR-TB) [10]. Multi-drug resistance TB occurs when mycobacterium do not respond to at least isoniazid and rifampicin, which are part of the 2 first line or standard anti-TB drugs. Extensive-drug resistance occurs when mycobacterium becomes resistant to most of the available drugs including most second line anti-TB drugs [5].

There is a global increase in the use of herbal medicines and developing countries tend to depend on these plants more than other populations primarily because of the limitations in modern healthcare facilities in addition to cultural preferences [11]. To date, phytomedicines have shown great potential in treating intractable infectious diseases for example TB [4]. Approximately $80 \%$ of the population in developing countries depend on traditional medicines for their primary health care needs [12]. In acknowledgement of this fact, the WHO declared a resolution on promoting the role of traditional medicine in health systems, a strategy for the African region. For most plants safety and efficacy profiles have not yet been identified and this has posed a major challenge in trying to merge traditional medicines and modern medicines in order to improve the health care system. There is a need, therefore, to evaluate and justify their respective pharmacological activities.

The family Combretaceae consists of approximately 20 genera and 600 species. This plant occurs mainly in tropical and subtropical areas, like Africa and Brazil [13]. The Combretaceae family of plants has been widely used as traditional medicines [14]. Use of these plants to treat scorpion and snake bites, and mental problems and their use for the relief of sore throats and colds, fever, chest coughs associated with tuberculosis, pneumonia and venereal diseases like syphilis is common in most African communities [15]. Studies on the genus have shown presence of several phytochemical constituents including alkaloids, saponins, tannins and cardiac glycosides $[16,17]$. To date there are over 27000 alkaloidbased compounds in the Dictionary of Natural Products (DNPs) [18]. Alkaloid molecules can act, depending on a type of amine functionality present in alkaloids, as either hydrogen- acceptor or hydrogen-donor for hydrogen bonding. This bonding is critically important for the interaction (binding) between targets, which may be enzymes, proteins and receptors for drugs, thereby, potentiating the drug effects in a pathology condition [19].

There is need for in vitro-screening of phytomedicines so that there is validation of their traditional use and for providing leads in the discovery of new active chemical principles $[3,20]$. The highly infectious nature of $\mathrm{Myco}$ bacterium tuberculosis restricts its use for large scale screening of probable drug candidates [21]. Mycobacterium smegmatis is a fast growing and non-pathogenic strain compared to the disease-causing strain $M$. tuberculosis. M. smegmatis has been found to display a similar drug sensitivity profile similar to $M$. tuberculosis [21] and, therefore, this organism can be used as a primary screen to shortlist compounds with antimycobacterial activity. The objectives of this study, therefore, was to evaluate the effects of alkaloid extracts from selected Combretum species on a model mycobacterium species, M. smegmatis.

\section{Methods \\ Reagents}

The following chemicals and equipment were used and these are: Phillips two-speed electric blender, 10\% Ethanolic acetic acid, ammonia solution, Middlebrook 7H9 media, casein hydrosylate, agar, an incubator, dimethyl sulphoxide (DMSO), dichloromethane (DCM), rifampicin, ciprofloxacin, 96-well microtitre plates, a Biokinetics Reader EL350, biosafety hazard safety cabinet level 2. All the chemicals used were obtained from Sigma Aldrich (Darmstadt, Germany) 


\section{Plant collection and preparation of extracts}

Combretum zeyheri and Combretum platypetalum leaves were collected in Norton, Zimbabwe, geographical location $17.8833^{\circ} \mathrm{S}, 30.7000^{\circ} \mathrm{E}, 1364 \mathrm{~m}$ above sealevel. Combretum molle and Combretum apiculatum leaves were collected in Centenary $\left(16.8^{\circ} \mathrm{S}, 31.1167^{\circ} \mathrm{E}\right.$, and $1156 \mathrm{~m}$ above sea level), Mashonaland Central Province, Zimbabwe in the summer period (January-February, 2013). The plants identity was authenticated and classified by Mr. Christopher Chapano, a taxonomist at the National Herbarium and Botanic Gardens (Harare, Zimbabwe). The samples were allocated a voucher specimen number N6E7, N9E7, C1E7 and C2E7 for C. zeyheri, C. platypetalum, C. apiculatum and C. molle respectively and herbarium samples were kept at the National Botanic and Herbarium Garden and the Department of Biochemistry, University of Zimbabwe. The dried plant leaves were ground using a two speed blender (Cole Parmer instruments company, Vernon Hills, USA). Alkaloid phytoconstituents were extracted from the plants using a polar solvent, $20 \mathrm{ml}$ of $10 \%$ ethanolic acetic acid after which the mixtures were left to stand for $4 \mathrm{~h}$ at room temperature a method described by Harbone [22] with modifications. Mixtures were filtered through a Whatman filter paper. The filtrate was concentrated by evaporation over a steam bath to a quarter of its original volume. To precipitate the alkaloid, concentrated ammonia solution was added in drops to the extract until it is in excess. Alkaloid precipitates were recovered by filtration using previously weighed filter paper after which $9 \%$ ammonia solution was added to wash the precipitates. The precipitates were dried in an oven at $60^{\circ} \mathrm{C}$ for $30 \mathrm{~min}$ and reweighed [23].

\section{Growth of mycobacteria}

Mycobacterium smegmatis, $\mathrm{Mc}^{2} 155$ was obtained from Professor Daniel Steenkamp of the Department of Clinical Laboratory Studies, University of Cape Town, South Africa. A volume of $100 \mathrm{ml}$ of liquid broth consisting of $0.52 \mathrm{~g}$ Middlebrook 7H9 media supplemented with $0.1 \mathrm{~g}$ casein hydrosylate was prepared using boiled distilled water, sterilised by autoclaving and used for the growth of mycobacterium at $37{ }^{\circ} \mathrm{C}$ under aerobic conditions.

\section{Determination of antimycobacterial activity}

The alkaloid extracts from the plants were used to determine the minimal inhibition concentration (MIC) and the minimal bactericidal concentration $(\mathrm{MBC})$ using the broth microdilution assay described by Martini and Eloff [24]. Extracts were initially dissolved in DMSO and, therefore, the effects of DMSO were also investigated on M. smegmatis. The alkaloid extracts were serially diluted with media from $1000 \mu \mathrm{g} / \mathrm{ml}$ up to $0.2 \mu \mathrm{g} / \mathrm{ml}$ using the broth. Aliquots of $100 \mu \mathrm{l}$ were placed into 96-well microtitre plates in duplicate. Rifampicin was used as the positive control. The plates were sealed with parafilm ${ }^{\mathrm{Tm}}$ paper and incubated in a container containing wet paper towel over night at $37{ }^{\circ} \mathrm{C}$ in an incubating shaker (Jeio Tech, Korea). Optical densities of the wells were read using a microplate reader (Tecan Genios-Pro microplate reader, GrÖdig, Austria) at $590 \mathrm{~nm}$. A solution of 3-(4, 5-dimethylthiazol-2-yl)-2, 5-diphenyltetrazolium bromide (MTT) was added and the plates were incubated for $2 \mathrm{~h}$. After the incubation, $25 \mu \mathrm{L}$ of DMSO was added to dissolve the purple formazan that would have been formed. The wells that did not show any colour change after MTT was added, indicated the concentration of the plant alkaloid extract that was able to inhibit mycobacterium growth whereas a purple colour change indicated mycobacterium growth [25]. MBCs of the alkaloids were determined on Middlebrook media 7H9 agar.

\section{Determination of drug efflux}

Accumulation and efflux of the fluoroquinolone, ciprofloxacin was performed in order to determine the effect of plant alkaloid extract on mycobacterium efflux pumps as described by Mortimer and Piddock [26] with some modifications. Mycobacterium were grown in Middlebrook $7 \mathrm{H} 9$ supplemented with casein hydrosylate media in 3 separate flasks containing $400 \mathrm{mls}$ media and grown over 2 days at $37{ }^{\circ} \mathrm{C}$. The mycobacteria were harvested by centrifugation at $3000 \mathrm{rpm}$ in a Hettich Rotofix 32 centrifuge (Tuttlingen, Germany) for $10 \mathrm{~min}$ in preweighed tubes and the supernatant discarded. Bacteria were then washed twice with $50 \mathrm{mM}$ sodium phosphate buffer (PBS) (pH 7.2). The cells were weighed and a volume needed to make up a volume of $40 \mathrm{mg} / \mathrm{ml}$ was made in $10 \mathrm{mM}$ PBS containing sodium azide. The mixture was incubated at $37{ }^{\circ} \mathrm{C}$ for $15 \mathrm{~min}$. Ciprofloxacin was added to the mixture to a final concentration of $20 \mu \mathrm{g} / \mathrm{ml}$. The mixture was incubated at $37{ }^{\circ} \mathrm{C}$ with shaking at $120 \mathrm{rpm}$ for $1 \mathrm{~h}$ (Lab Companion, Jeio Tech, Seoul, South Korea). The sample was divided into two aliquots a two-third and one-third volume sample which was centrifuged at $3000 \mathrm{rpm}$ for $5 \mathrm{~min}$. The supernatant was discarded and the pellet was weighed. PBS was added to the one third sample to make up to a concentration of $40 \mathrm{mg} / \mathrm{ml}$, this tube representing a sample without glucose. After discarding the supernatant and weighing the pellet PBS containing $1 \mathrm{M}$ glucose was added to the two-third sample which was further subdivided into 3 equal aliquots of $40 \mathrm{mg} / \mathrm{ml}$ containing either reserpine, DMSO, or the alkaloid plant extract from Combretum zeyheri.

In order to rule out the effect of the solvent DMSO, was also added in one of the tubes as it was the organic solvent used to dissolve reserpine and the alkaloid extract. The samples were mixed by vortexing before being 
incubated for $30 \mathrm{~min}$ at $37^{\circ} \mathrm{C}$ with shaking at $120 \mathrm{rpm}$. After incubation, cells were washed with chilled phosphate buffer and re-centrifuged for $10 \mathrm{~min}$ at $4000 \mathrm{rpm}$. After the supernatant was discarded, the pellet was resuspended in glycine hydrochloride $3.0 \mathrm{ml}(0.1 \mathrm{M}$, $\mathrm{pH}$ 3.0) with agitation to ensure exposure of the cells to the lysis buffer. The samples were incubated at $37 \mathrm{C}$, $120 \mathrm{rpm}$ for overnight. The samples were then centrifuged for $10 \mathrm{~min}$ at $3000 \mathrm{rpm}$ to sediment cell debris. The fluorescence of ciprofloxacin in the supernatant was determined at the excitation and emission wavelengths of $270 \mathrm{~nm}$ and $452 \mathrm{~nm}$ respectively using an RF - 1501 Shimadzu spectrofluorimeter (Shimadzu Cooperation, Tokyo, Japan). Both supernatant samples from the intact cells (representing efflux samples) and the lysed cells (representing influx samples) were quantified for ciprofloxacin using a standard curve. To rule out interference from the reserpine and the plant extracts, their fluorescence was determined at the same excitation and emission wavelength as ciprofloxacin.

\section{Time-kill assay}

Time-kill assays were carried out with modifications from Oladosu et al., [27]. M. smegmatis was grown overnight at $37{ }^{\circ} \mathrm{C}$ in Middlebrook 7H9 media supplemented with casein hydrolysate. The plant alkaloid extracts were serially diluted with media from $1000 \mu \mathrm{g} / \mathrm{ml}$ up to $0.2 \mu \mathrm{g} / \mathrm{ml}$ to make ten 2-fold microdilutions for the microbroth dilution assay. Aliquots of $100 \mu \mathrm{l}$ were plated onto 96-well microtitre plates in duplicate. Rifampicin was used as the positive control at 2-fold increasing concentrations of from $0.1 \mu \mathrm{g} / \mathrm{ml}$ to $50 \mu \mathrm{g} / \mathrm{ml}$. The extracts and rifampicin were cultured with the inoculum at a final concentration of $1 \times 10^{6} \mathrm{cfu} / \mathrm{ml}$. In order to rule out interference from the media the plant extract was incubated with media only. The plates were sealed with parafilm $^{\mathrm{Tm}}$ paper and incubated in a container containing wet paper towel over night at $37 \mathrm{C}$ in an incubating shaker (Jeio Tech, Korea). At defined time intervals (0, $2,4,6,8$, and $24 \mathrm{~h}$ ), the size of the bacterial population was quantified to characterise the effect of the different extract concentrations. This was done by plating $10 \mu \mathrm{l}$ aliquots of each dilution $(10 \mu \mathrm{l}$ samples diluted up to $1 \mathrm{ml}$ with media) and plated on $40 \mathrm{ml}$ solid agar plates. Only $250 \mu \mathrm{g} / \mathrm{ml}, 125 \mu \mathrm{g} / \mathrm{ml}$, and $63 \mu \mathrm{g} / \mathrm{ml}$ extract concentrations were plated. Plates were incubated for $24 \mathrm{~h}$ at $37^{\circ} \mathrm{C}$. The number of viable organisms were counted as cfu/plate. Surviving organisms were determined by the plate count method at sampling time and enumerated. Average duplicate ( 2 plates from each replicate dilution) counts were multiplied by the dilution factor to derive the concentration of cells as $\mathrm{cfu} / \mathrm{ml}$. The percentage reduction from initial microbial population for each time point was calculated to express the change (reduction or increase) of the microorganism population relative to a starting inoculum. The change was determined as follows:

$$
\begin{aligned}
& \% \text { Reduction }=(\text { initial count }- \text { count at } x \text { interval } / \\
& \text { initial count) } \times 100
\end{aligned}
$$

The number of surviving microorganisms in the extract was determined by plate-count method at sampling time and enumerated. Optical densities signifying bacterial cell density of the wells were also read using a Genios Pro microplate reader (Tecan Instruments, Grodig, Austria) at $590 \mathrm{~nm}$. The results were analysed using ANOVA with graph pad ${ }^{\mathrm{Tu}}$ version 5 for Windows (Graph pad ${ }^{\mathrm{Tw}}$ Software Inc. Scan Diego, California. USA).

\section{Statistical analyses}

Numerical data was analysed using graph pad ${ }^{\mathrm{Tu}}$ version 5 for Windows (Graph pad ${ }^{\mathrm{m}}$ Software Inc. Scan Diego, California. USA). Statistical analysis was carried out using One-way ANOVA where values of $\mathrm{P}<0.05$ are regarded as significant ( $95 \%$ confidence interval). A post-hoc analysis (Dunnet's multiple comparison test) was used Graphpad Prism (Version 5.0, Graph pad Software Inc, San Diego, USA).

\section{Results}

\section{Extraction of plant phytoconstituents and} antimycobacterial activity determination

Alkaloid extracts from 4 plant species namely: Combretum apiculatum, Combretum molle, Combretum platypetalum and Combretum zeyheri were tested for antimycobacterial activity. Extraction was carried out using 10\% acetic ethanolic acid, and percentage yields are shown in Table 1 . The effects of the solvent was determined and the results are shown in Fig. 1. A DMSO solvent concentration of $2.5 \%$ was used for all the subsequent assays. In order to quantify the activity of alkaloid extracts from the four plant species, the broth microdilution method was used. This allowed determination of the minimum inhibitory concentration and subsequently the minimum bactericidal concentration. Varying concentrations of the plant extracts were tested and these ranged from $1000 \mu \mathrm{g} / \mathrm{ml}$ to $2 \mu \mathrm{g} / \mathrm{ml}$ attained by 2 -fold dilutions. Of the four plant

Table 1 The extractive values and percentage yields of crude $10 \%$ ethanolic acetic acid extracts

\begin{tabular}{lcc}
\hline Name of plant species & $\begin{array}{c}\text { Amount extracted } \\
\text { per } 50 \mathrm{~g} \text { sample }\end{array}$ & Percentage yield (\%) \\
\hline C. platypetalum & 0.108 & 0.432 \\
C. apiculatum & 0.049 & 0.196 \\
C. zeyheri & 0.605 & 2.42 \\
C. molle & 0.371 & 1.484 \\
\hline
\end{tabular}

The alkaloids were extracted according to the method by Harbone [23] 


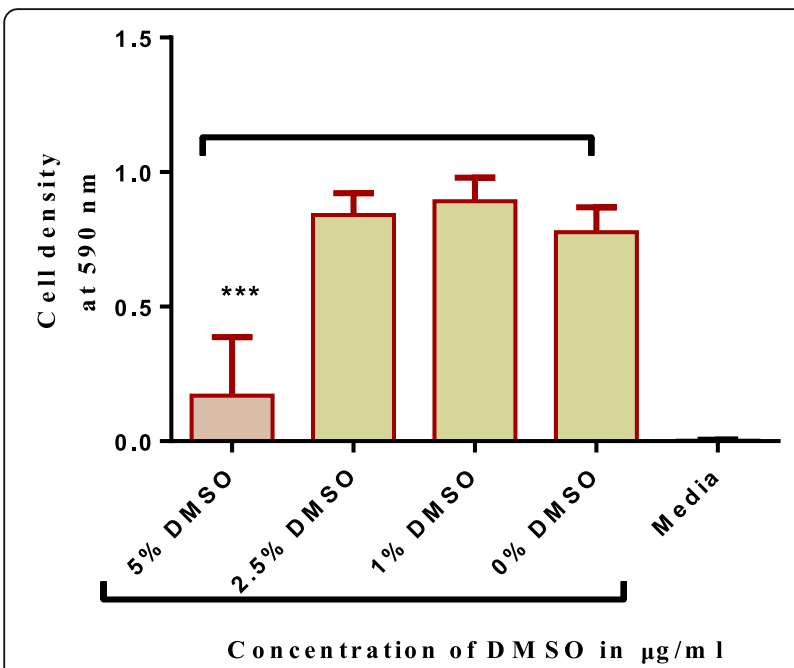

Fig. 1 The effect of different concentrations of DMSO on $M$. smegmatis. Mycobacterium smegmatis was grown in broth and exposed to varying concentrations of DMSO in 96-well microplates. *** $P<0.001$ in comparison with the $0 \%$ DMSO. Values are the mean $\pm S D$ for $N=6$

species extracts tested, C. zeyheri alkaloid extract was the most effective in inhibiting the growth of Mycobacterium smegmatis. Rifampicin was used as the positive control whilst the negative control was cells and media only (Fig. 2). Figure 3 shows the effects of the C. zeyheri alkaloids on the growth of mycobacteria. MICs of $1000 \mu \mathrm{g} / \mathrm{ml}$, $>1000 \mu \mathrm{g} / \mathrm{ml}$ and $125 \mu \mathrm{g} / \mathrm{ml}$ were obtained for C. molle, $C$. platypetalum and C. zeyheri respectively (Table 2 ). The purple formazan colour that was quantified spectrophotometrically indicated presence of viable cells showing mycobacterium growth (Fig. 4). Wells that showed no colour change after addition of MTT (yellow colour) represented concentration of the plant extracts that were able to inhibit mycobacterium growth $(1000-125 \mu \mathrm{g} / \mathrm{ml})$. Combretum platypetalum alkaloid extracts also showed that they had antimycobacterial effects but the these effects were lower than those of C. zeyheri (Fig. 5)

\section{Time-kill kinetics of alkaloid extracts from C. zeyheri on Mycobacterium smegmatis}

Alkaloid extracts from Combretum zeyheri showed concentration-dependent killing with a minimum inhibitory concentration of $125 \mu \mathrm{g} / \mathrm{ml}$ and a minimum bactericidal concentration of $250 \mu \mathrm{g} / \mathrm{ml}$ using the broth microdilution method (Fig. 6). Concentrations from 0$1000 \mu \mathrm{g} / \mathrm{ml}$ were used. In order to also determine killing capacity of the extract; a time-kill assay was carried out. For the time-dependent assay, a range of three concentration $63 \mu \mathrm{g} / \mathrm{ml}, 125 \mu \mathrm{g} / \mathrm{ml}$ and $250 \mu \mathrm{g} / \mathrm{ml}$ were used. The antimycobactericidal capacity of the alkaloid extract from C. zeyheri was highly time-dependent. At the highest concentration of $250 \mu \mathrm{g} / \mathrm{ml} 100 \%$ bactericidal activity was achieved after a time period of $8 \mathrm{~h}$. No growth was observed after $24 \mathrm{~h}$. At $250 \mu \mathrm{g} / \mathrm{ml}$ the bactericidal activity of the extract was quite efficient and time-dependent with a decrease in the number of colony forming units per $\mathrm{ml}(\mathrm{cfu} / \mathrm{ml})$ over time intervals 0 , $2,4,6,8$ and $24 \mathrm{~h}$ respectively. At a concentration of $125 \mu \mathrm{g} / \mathrm{ml}$ a decrease in the number of $\mathrm{cfu} / \mathrm{ml}$ was observed. The antimycobactericidal capacity was moderate with $\geq 90 \%$ killing achieved after $8 \mathrm{~h}$ calculated as the percentage reduction [27]. For both the 125 and $250 \mu \mathrm{g} / \mathrm{ml}$, there was a decrease in the colony forming units which was time-dependent. In terms of efficiency of killing, the graph shows that the $250 \mu \mathrm{g} / \mathrm{ml}$ was more effective than $125 \mu \mathrm{g} / \mathrm{ml}$ at 0 and $4 \mathrm{~h}$ post incubation. However, in both cases of the concentrations, $100 \%$ killing activity was not achieved although concentration-dependent killing was achieved (Fig. 6). At $63 \mu \mathrm{g} / \mathrm{ml}$, similar growth with the control was obtained. After $24 \mathrm{~h}$ M. smegmatis suspension in the $63 \mu \mathrm{g} / \mathrm{ml}$ sample was aggregated as characterised by the cloudy appearance of cells and this was probably due to increased mycobacterium cell density. Alkaloid extracts of C. zeyheri showed concentration-dependent killing with a decrease in the number of surviving colonies being observed from the lowest to the highest concentrations. A significant decrease in population of test organisms was observed at each interval with the percentage reduction in viable cell count observed to be from $40 \%$ to $90 \%$ and $13.3 \%$ to $100 \%$ between 2 to $24 \mathrm{~h}$ of interaction at the $125 \mu \mathrm{g} / \mathrm{ml}$ concentration and at $250 \mu \mathrm{g} / \mathrm{ml}$ concentration respectively. This represented a significant decrease in microbial population particularly at $250 \mu \mathrm{g} / \mathrm{ml}$.

\section{Effect of plant extracts on Mycobacterium smegmatis efflux pumps}

Of the 4 Combretaceae plant species tested; alkaloid extracts from Combretum zeyheri were the most effective in inhibiting drug efflux. The effect of extracts from $C$. zeyheri on efflux pumps in M. smegmatis was determined using the ciprofloxacin accumulation assay. Active accumulation of ciprofloxacin in $M$. smegmatis was monitored in the presence and absence of plant extracts and for comparison accumulation of ciprofloxacin was monitored in the presence of reserpine, a known efflux pump inhibitor. The ability of the plant alkaloid extracts in inhibiting efflux pump activity in M. smegmatis was comparable to that of reserpine a known efflux pump inhibitor. As shown in Fig. 7, there was no significant difference between the sample containing reserpine and glucose versus the sample containing the extract from $C$. zeyheri and glucose indicating that reserpine inhibited drug efflux. Similarly the alkaloid extract inhibited the efflux of ciprofloxacin from the cells to the same extent as reserpine. 


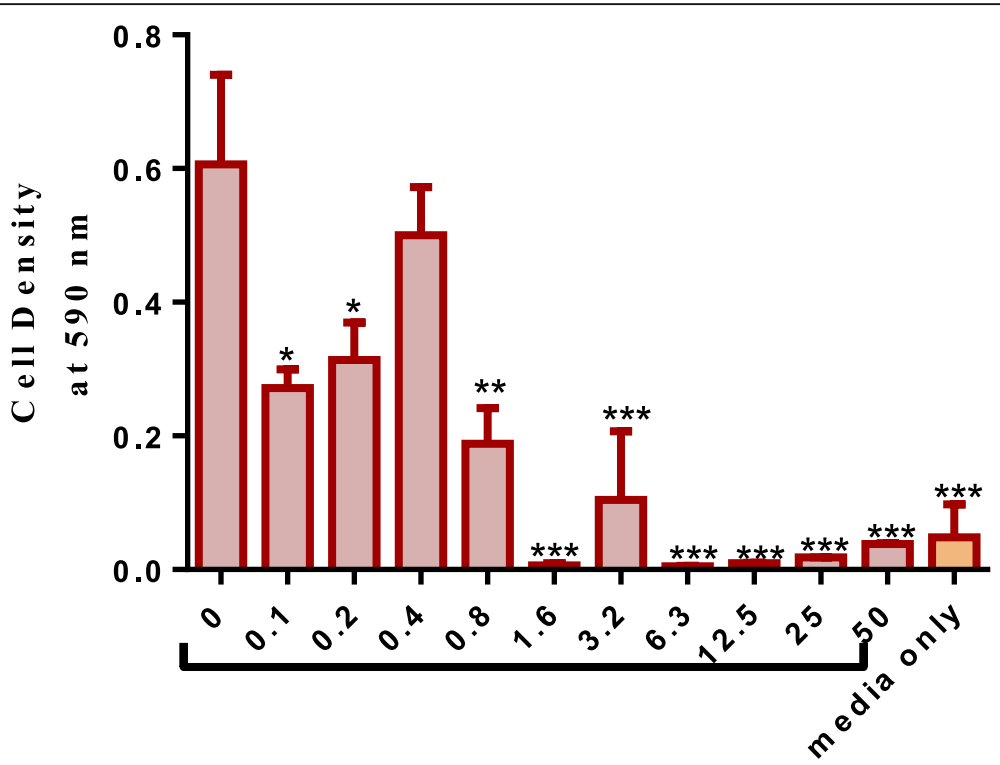

Concentration of rifam picin $(\mu \mathrm{g} / \mathrm{m} \mathbf{l})$

Fig. 2 The effects of rifampicin (positive control) on the growth of mycobacterium in broth. M. smegmatis were grown and exposed to increasing concentrations of rifampicin in a 96-well microplate. Values are the mean of \pm SD for $n=4$ for duplicate measurements $* P<0.05 * * P<0.01$, *** $P<0.001$ in comparison with the cells exposed to the zero concentration of extract

\section{Discussion}

Due to the emergence of multi-drug resistant mycobacterium, new alternatives for the treatment of tuberculosis are urgently needed. Statistics show that every year, 8 million people are infected with TB whilst 2 million deaths are reported annually [28]. When a patient becomes resistant to anti-tuberculosis drugs, particularly isoniazid and rifampicin, they have a $40 \%$ chance of survival regardless of their HIV status [6]. In addition, TB treatment protocols are long in duration causing patients to default from taking their medication and there is no sufficient treatment for multi-drug resistant $\mathrm{TB}$ (MDR-TB) [29]. At least 24 species of Combretum are well known in African traditional medicine and are used

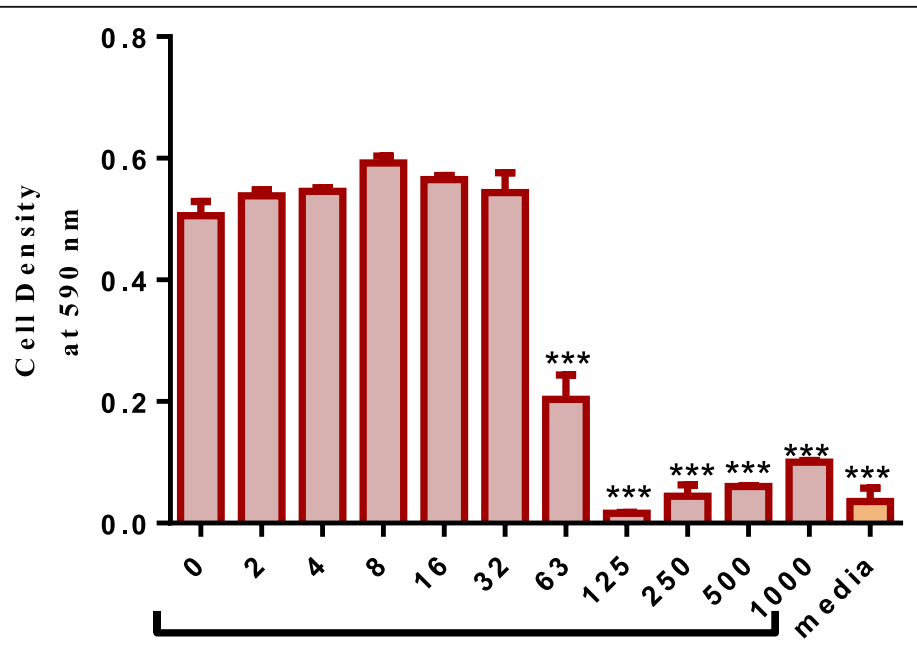

Concentration of $C$. zeyherialkaloid extract $(\boldsymbol{\mu} / \mathrm{m} \mathbf{l})$

Fig. 3 The growth inhibitory properties of alkaloid extracts from C. zeyheri on Mycobacterium smegmatis. The broth microdilution method was used to determine growth inhibitory properties of extracts using a 96-well microtitre plate. A minimum inhibitory concentration of $125 \mu \mathrm{g} / \mathrm{ml}$ was observed and the optical densities of the wells were read using a microplate reader (Tecan Genios-Pro microplate reader, GrÖdig, Austria) at $590 \mathrm{~nm}$. Values are the mean of $\pm \mathrm{SD}$ for $n=4 .^{* * *} P<0.001$ in comparison with the cells exposed to the zero concentration of extract 
Table 2 The effects of the alkaloid -enriched leaf extracts against Mycobacterium smegmatis at $1000 \mathrm{\mu g} / \mathrm{ml}$

\begin{tabular}{lll}
\hline Combretum species & Activity at $1000 \mu \mathrm{g} / \mathrm{ml}^{\mathrm{a}}$ & $\mathrm{MIC}(\mu \mathrm{g} / \mathrm{ml})^{\mathrm{b}}$ \\
\hline C. platypelatum & Moderately Active & $>1000$ \\
C. apiculutum & Inactive & $>1000$ \\
C. molle & Moderately active & 1000 \\
C. zeyheri & Active & 125 \\
\hline
\end{tabular}

${ }^{\mathrm{a}}$ Activity at $1000 \mu \mathrm{g} / \mathrm{ml},{ }^{\mathrm{b}}$ Minimum inhibitory concentration

for the treatment of a variety of ailments and diseases, ranging from scorpion stings and snake bites, mental problems, heart and worm remedies and microbial infections [30]. The therapeutic effects of these medicinal plants is due to the presence of particular substances in plants most of which are phenols or their derivatives. These phytochemicals may not have direct physiological activity within the plant itself but have significant biological effects on animals [4].

Differences in yields for the four Combretum species were observed on extraction of the alkaloid phytoconstituents. This is not unusual as variations in biological activity and quantity of the phytochemicals present in the plant extract occur due to various reasons that include: plant age, differences in geographical areas in harvest sites and also seasonal variations [31].

When patients are inadequately exposed to antituberculosis drugs, this may result in the emergence of resistant mycobacterium [31]. Drug resistance may be classified as phenotypic or genotypic resistance. Phenotypic drug resistance occurs when mycobacterium are only slightly affected by the anti-tuberculosis drugs such as rifampicin. This type of resistance maybe due to porin loss, increased efflux pump activity or presence of drug-modifying enzymes which will reduce desired drug concentrations intracellularly. Genotypic drug resistance is usually linked to mutations in mycobacterium genome and most of these mutations are known [9].

The uses of traditional medicines as alternative forms of health care provision are accepted, particularly in developing countries [32]. This led us to the investigation of the effects of alkaloid extracts from four Combretaceae family plant species on anti-mycobacterium activity. The need to use plant species belonging to the Combretaceae family of plants and investigating their effects on $M$. smegmatis was based on the ethnomedicinal use of these plants in Zimbabwe [33, 34] and other African countries in this region where the plants are used in the treatment of symptoms associated with TB such as persistent cough, chest pains and fever [8].

Using the broth microdilution method it was shown that alkaloid extract from Combretum zeyheri was the most potent against the mycobacterium with a minimum inhibitory concentration of $125 \mu \mathrm{g} / \mathrm{ml}$ and a minimum bactericidal concentration of $250 \mu \mathrm{g} / \mathrm{ml}$. Extracts from $C$. molle and C. platypetalum were inactive with MICs above $1000 \mu \mathrm{g} / \mathrm{ml}$ whilst extracts from C. apiculatum were inconclusive. The criteria for an active plant extract has been given as MIC values of $128 \mu \mathrm{g} / \mathrm{ml}$ or $\mathrm{IC}_{50}$ values of less than $100 \mu \mathrm{g} / \mathrm{ml}$ [35]. Activity with plant extracts is considered to be moderate when $100<\mathrm{MIC}<625 \mu \mathrm{g} / \mathrm{ml}$ [28]. In this regard, the alkaloid extract of C. zeyheri can be considered to have significant antimycobacterial effects. An MIC above $1000 \mu \mathrm{g} / \mathrm{ml}$ for crude extracts is categorised as being inactive against mycobacterium. This is because these are crude extracts of the plants and so MICs will not be a reliable indicator of the isolation of a potent antimycobacterial compound, thus, the lower the MIC, the more significant the result [36]. The front-line anti-TB drugs, such as rifampicin have MICs in the range of 0.025 $-0.20 \mu \mathrm{g} / \mathrm{ml}$ and if compared to the activity of any new extracts, a new compound must have an activity in the

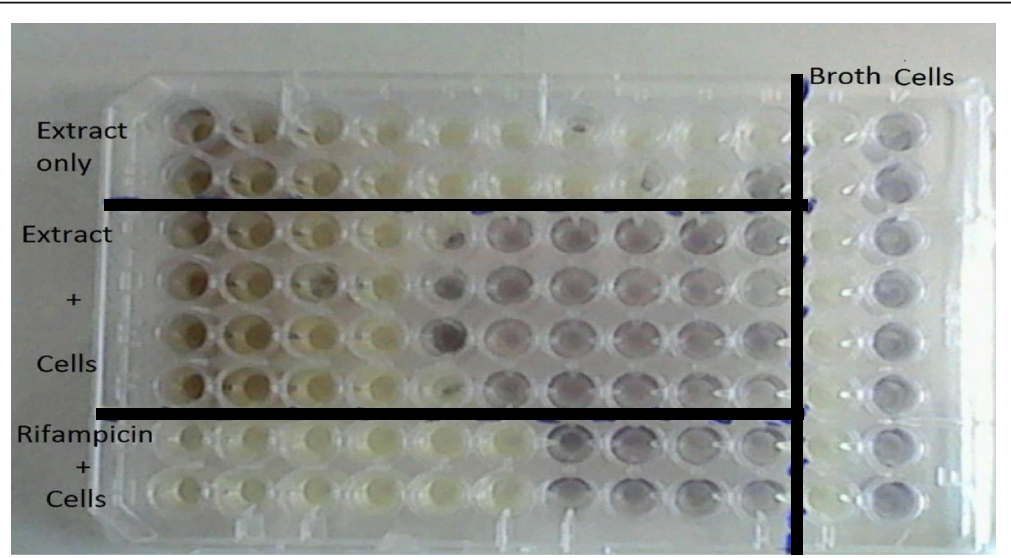

Fig. $4 \mathrm{MTT}$ assay showing the growth inhibitory effects of alkaloid extracts from C. zeyheri on M. smegmatis. Viable cells are coloured purple whilst metabolically inactive cells are coloured yellow. The intensity of the purple also shows levels of cell activity 


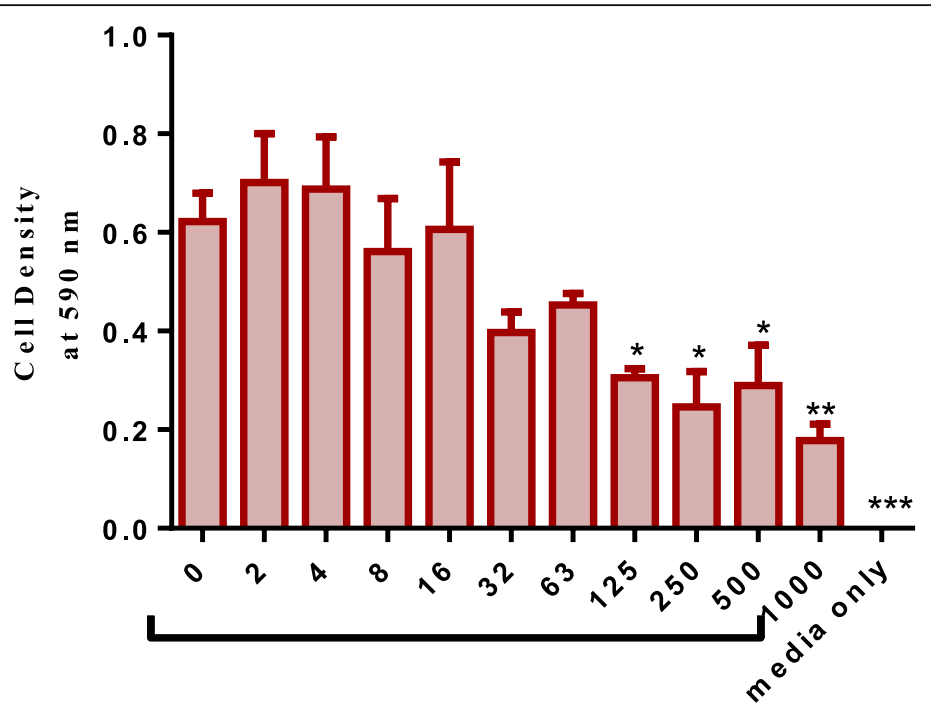

Concentration of $C$. platypelatum alkaloid extract $(\mu \mathrm{g} / \mathrm{ml})$

Fig. 5 The effects of $C$. platypetalum alkaloid extracts on mycobacterium in broth. M. smegmatis were grown in broth and exposed to increasing concentrations of $C$. platypetalum leaf alkaloid extracts in a 96-well microplate. Values are the mean of \pm SD for $n=4$. ${ }^{*} P<0.05$; ${ }^{* *} P<0.01$ in comparison with the cells exposed to the zero concentration of extract

same range. However, these are crude extracts on which no further purification process has been carried out, hence, they may be considered active at higher concentrations as well particularly for C. zeyheri.

A time-kill assay aims to determine not only concentration-dependent killing capacity of drugs or plant extracts, but also the time - dependent killing activity of these agents. A wide range of concentrations of the drug or extract are used and mycobacterial killing at different time points is determined. This is done during exposure of the mycobacterium to the drug or plant extract being used. Therefore, instead of only obtaining results at the end - point; more detailed information is provided as to the different killing capacities of these agents at fluctuating concentrations [9]. This study, unlike a MIC/MBC assay, allows the determination of the speed of bactericidal activity of the extract [27].

An ideal anti-TB should show a high killing rate with a concomitant decrease in mycobacterial load reducing the risk of developing resistance or spreading the disease. The results of the present study provide insight into the in vitro killing dynamics of plant species belonging to the Combretaceae family of plants with respect to the killing capacity (concentration-dependence) and the

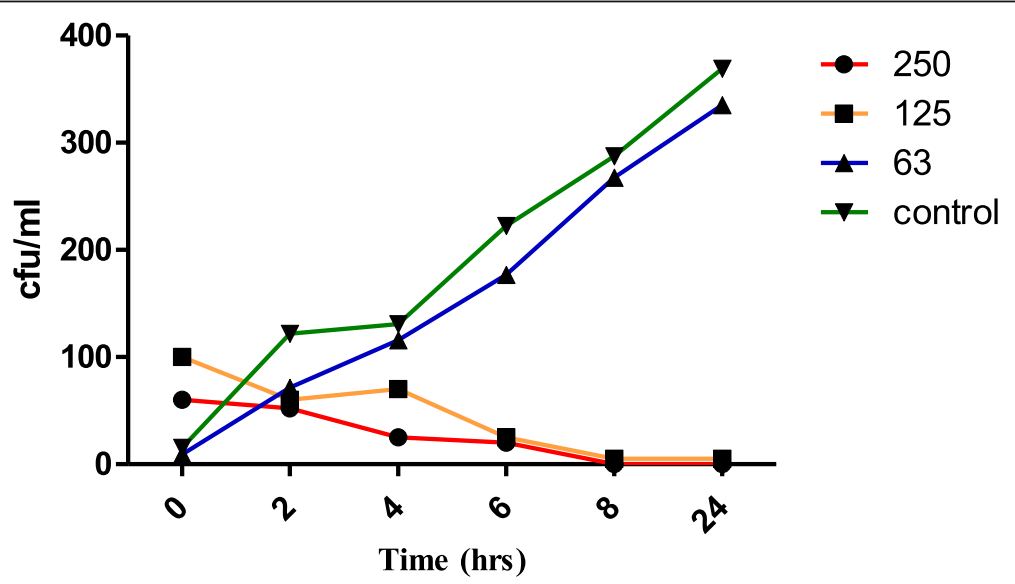

Fig. 6 Time dependent and concentration - dependent bactericidal effect of alkaloid extracts from C. zeyheri on M. smegmatis. Cultures of M. smegmatis standardised to $1 \times 10^{6} \mathrm{cfu} / \mathrm{ml}$ were exposed to alkaloid extracts from C. zeyheri at 2-fold increasing concentrations from $2 \mu \mathrm{g} / \mathrm{ml}$ to $1000 \mathrm{\mu g} / \mathrm{ml}$ over $24 \mathrm{~h}$ at $37^{\circ} \mathrm{C}$. After 2, 4, 6, 8 and $24 \mathrm{~h}$ of exposure samples were taken to determine number of surviving populations at 0,63 , 125 , and $250 \mu \mathrm{g} / \mathrm{ml}$ 


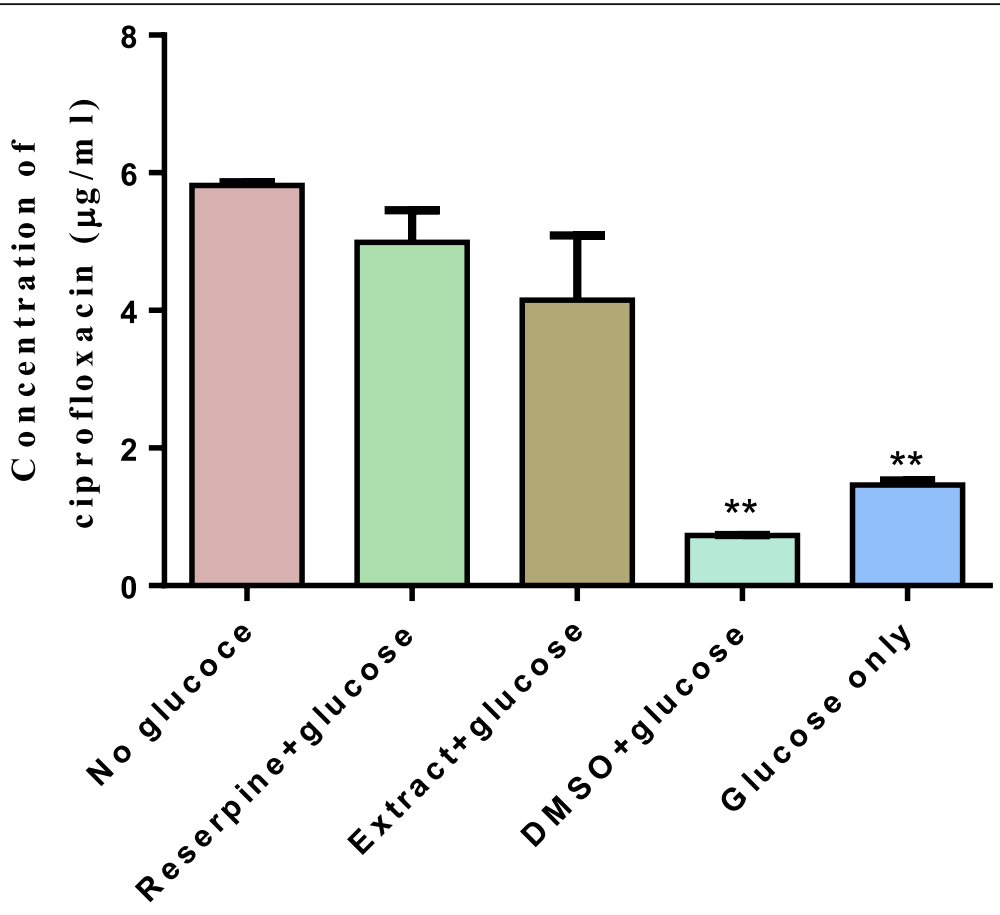

\section{S a m ple of exposure}

Fig. 7 Effects of alkaloid extracts from C. zeyheri on drug accumulation in mycobacteria. Cells were loaded with ciprofloxacin and incubated for an hour. Cells were centrifuged, supernatant removed and exposed to the various compounds in buffer with glucose. One sample was exposed to the buffer alone with no glucose being added and this was the control. Cells were then centrifuged again and lysed with glycine-HCl. Cell debris was collected by centrifugation and the amount of ciprofloxacin in the supernatant quantified at excitation and emission wavelengths of $270 \mathrm{~nm}$ and $452 \mathrm{~nm}$ respectively using an RF1501 Shimadzu spectrofluorimeter. Values are the mean of \pm SD for $n=2$ for duplicate determinations ${ }^{*} P<0.01$ in comparison with the cells exposed to glucose only

rate of killing (time-dependence). Of interest is the adaptation or acclimatisation phase of microorganisms which was observed between the $2 \mathrm{~h}$ and $4 \mathrm{~h}$ interval at $125 \mu \mathrm{g} / \mathrm{ml}$. This phase is characterised by some form of growth though minimal as microorganisms are acclimatising to the environment. However, because microbial cells were in a toxic environment, cell death occurred soon after and this was quite rapid at $250 \mu \mathrm{g} / \mathrm{ml}$. A sharp decrease in microbial population was to be expected at higher concentrations $(500-1000 \mu \mathrm{g} / \mathrm{ml})$. However, the nature of the assay required concentration values close to those of the MIC of the most potent plant species.

Resistance of mycobacterium to anti-TB agents is hinged on a number of factors which include presence of efflux pumps which the major factor is contributing to intrinsic resistance [37]. Also, the nature of the mycobacterium cell wall makes it extremely impermeable to a wide range of agents due to its complex system of mycolic acids intercalated to a whole range of lipids and polymers [38].

Glucose transport systems in $M$. smegmatis belong to a family of transporters called the ATP-binding cassette (ABC) transporter family. Mycobacterium tuberculosis possesses five sugar import systems. However, Mycobacterium smegmatis has 28 such transporters which it also uses to pump out foreign compounds [39]. $M$. smegmatis is the microbial species of choice to use in learning more about mycobacterium physiology in vitro [21]. Furthermore, M. smegmatis is nonpathogenic in nature and is also fast growing [40]. Ciprofloxacin is a potent antimycobacterial agent (second line) that targets genetic material specifically DNA gyrase and topoisomerase IV. In order to study the transport of agents across cell membranes a detection compound must be utilized. Detection compounds vary and include use of radioactive isotopes of common efflux pump substrates [37]. In this study, ciprofloxacin was used to quantify the accumulated amount inside the cell, thereby, assessing the effects of plant extracts on the drug pumping activity of ATPbinding cassette proteins in M. smegmatis.

Plant alkaloid extracts from $C$. zeyheri were the most potent of the four plant extracts in inhibiting the transport of ciproflocaxin. Reserpine is a plant alkaloid-based drug which was used clinically as an antihypertensive agent and as an anti-psychotic agent as well, although 
rarely used nowadays clinically due to toxic adverse effects [41]. It is a known efflux pump inhibitor. Reduced levels of ciprofloxacin were pumped out of the mycobacterial cells compared to the cells incubated with glucose and hence, more of the drug accumulated within the cell. Though comparable with the activity observed with reserpine, the extract did not result in greater accumulation of the drug inside the cells. Considering the moderate MIC of extracts from C. zeyheri $(125 \mu \mathrm{g} / \mathrm{ml})$, and comparable efflux pump inhibition to a known inhibitor, reserpine, the results suggest that besides possessing antimycobacterial activity, inhibition of efflux pumps could be a mechanism of action of these extracts [42].

There are many mechanisms by which phytochemicals may act on Mycobacteria and these include inhibition of cell wall synthesis, protein synthesis, interference with membrane integrity and others [43]. The aim of this study was first determine if an alkaloid extract had an effect on the growth of M. smegmatis. Since Mycobacteria are known to be inherently resistant to antimycobacterial agents because of the complex cell wall, and also because they pump out xenobiotics including anti-TB drugs, we tested if the antimycobacterial action of the alkaloid extracts could be due to interference with drug efflux. Our results show that the alkaloid extract prevented the efflux of ciprofloxacin from $M$. smegmatis. These findings would assist in the isolation of alkaloid compounds that have efflux inhibitory activity in Mycobacteria from this plant. There are reports of increased efflux pump expression in Mycobacterium tuberculosis in clinical isolates and efflux pump inhibitors such as verapamil have been used to enhance the antimycobacterial effects $[44,45]$. Thus, inhibition of efflux pumps should be manipulated as a target for new antimicrobial agents in drug development. Furthermore, if such promising antimicrobial effects are possessed with crude extracts that have not undergone an isolation and purification process then the extraction of the active compound responsible for these effects might result in greater inhibitory activity.

\section{Conclusions}

The alkaloid extracts from the plant species, C. zeyheri, were the most potent and displayed potent antimycobacterial activity towards $M$. smegmatis. In addition not only was there concentration-dependent killing capacity observed but also, time time-dependent killing activity as well. The extracts showed potential efflux-pump inhibitory activity, hence, further studies of this plant may lead to isolation of the bioactive compound. It is, therefore, essential to carry out isolation, purification and antimycobacterial evaluation of phytochemicals from Combretum zeyheri.

\section{Abbreviations}

ABC: ATP binding Cassette proteins; cfu: Colony forming units;

DMSO: Dimethyl sulphoxide; DNPs: Dictionary of Natural Products; INH: Isoniazid; MBC: Minimum bactericidal concetrations; MDR: TB-Multidrug resistant tuberculosis; MIC: Minimum inhibitory concentration; MTT: 3-(4, 5dimethylthiazolyl)-2, 5-diphenyltetrazolium bromide; RIF: Rifampin; TB: Tuberculosis

\section{Acknowledgements}

The authors acknowledge the assistance of Mr. Simbarashe Sithole for technical assistance during the course of the project.

\section{Funding}

Support from the International Science Programmes (ISP) through the International Program in the Chemical Sciences (ISP-IPICS: ZIM01, Uppsala University, Uppsala, Sweden). ISP -IPICS: ZIM01 supported the research under the title "Biomolecular Interactions Analyses".

\section{Availability of data and materials}

The data sets generated during and/ analysed during the current study are available in the University of Zimbabwe Digital Collections Repository: Postgraduate Thesis and Undergraduate Dissertations http://digitalcollections. uz.ac.zW:8080/xmlui and from the corresponding author on reasonable request.

\section{Authors' contributions}

TN and RM conducted the experimental studies and data analyses. SM conceptualized, designed and directed the study. TN, RM and SM finalized the manuscript. All authors read and approved the final manuscript.

\section{Authors information}

Dr. Stanley Mukanganyama is an associate professor of Biochemistry at the University of Zimbabwe. He holds a PhD in Biochemistry and specialised in drug metabolism, particularly the contribution of Phase II enzyme systems in xenobiochemistry. $\mathrm{He}$ is a member of the Biochemistry and Molecular Biology Society of Zimbabwe (BMBSZ), is the Head of the Department of Biochemistry and the In-country president of the Natural Products Research of Eastern and Central Africa (NAPRECA-Zimbabwe. Ms. Tafadzwa Nyambuya (B. Pharmacy Honours), is a practicing pharmacists. Ms. Ruvimbo Mautsa (BSC. Hons) is Teaching Assistant and M.Phil. student in the Department of Biochemistry, University of Zimbabwe.

\section{Competing interests}

The authors declare that they have no competing interests.

\section{Consent for publication}

Not applicable.

\section{Ethics approval and consent to participate}

The study was approved by the Joint Research Ethics Committee for the University of Zimbabwe, College of Health Sciences and Parirenyatwa Group of Hospitals. (JREC Ref 338/2014) Harare, Zimbabwe).

\section{Author details}

${ }^{1}$ School of Pharmacy, College of Health Sciences, University of Zimbabwe, Mt. Pleasant, Harare, Zimbabwe. ${ }^{2}$ Department of Biochemistry, University of Zimbabwe, P.O. Box MP 167, Mt. Pleasant, Harare, Zimbabwe.

Received: 2 December 2016 Accepted: 14 February 2017

Published online: 23 February 2017

\footnotetext{
References

1. Dheenadhayalan V, Delogu G, Sanguinetti M, Fadda G, Brennan MJ. Variable expression patterns of Mycobacterium tuberculosis PE_PGRS Genes: evidence that PE_PGRS16 and PE_PGRS26 are inversely regulated in vivo. J Bacteriol. 2006;188:3721-3725.

2. Semenya SS, Maroyi A. Medicinal plants used for the treatment of tuberculosis by bapedi traditional healers in Three Districts of the Limpopo Province, South Africa. Afr J Tradit Complement Altern Med. 2013;10:316-23.

3. McGaw LJ, Lall N, Meyer JJ, Eloff JN. The potential of South African plants against mycobacterium infections. J Ethnopharmacol. 2008;119:482-500.

4. TB Facts. https://www.tballiance.org/. Accessed 18 Feb 2017.
} 
5. WHO. WHO Global Tuberculosis Report. In: WHO Library Cataloguing-inPublication Data. 20th ed. Geneva: WHO Press; 2015.

6. WHO, 2016, http://www.who.int/mediacentre/factsheets/fs104/en/. Accessed 30 Nov 2016,

7. Mitchison DA. Antimicrobial therapy of tuberculosis: justification for currently recommended treatment regimens. Semin Respir Crit Care Med. 2009;25:307-15

8. Magwenzi R, Nyakunu C, Mukanganyama S. The effect of selected Combretum species from Zimbabwe on the growth and drug efflux of Mycobacterium aurum and Mycobacterium smegmatis. J Microbial Biochem Technol. 2014;10:1948-5948.

9. Steenwinkel J, Knegt GJ, Kate MT, Belkum A, Verbrugh HA, Kremer K, Soolingen D, Woudenberg IAJM. Time-kill kinetics of anti-tuberculosis drugs, and emergence of resistance, in relation to metabolic activity of Mycobacterium tuberculosis. J Antimicrob Chemother. 2010;10:1-8.

10. Gupta AK, Chauhan DS, Srivastava K, Das R, Batra S, Mittal M, Goswami P, Shinghai N, Sharma VD. Estimation of efflux mediated multi-drug resistance and its correlation with expression levels of two major efflux pumps in mycobacterium. J Commun Dis. 2006;38:246-54.

11. Debas HT, Laxminarayan R, Straus SE. Complementary and Alternative Medicine. Chapter 69. In: Jamison DT, Breman JG, Measham AR, et al, editors. Disease Control Priorities in Developing Countries. 2nd edition. Washington (DC): The International Bank for Reconstruction and Development/The World Bank. New York: Co-published by Oxford University Press; 2006.

12. WHO. Report Global tuberculosis control: Surveillance, Planning, Financing, World Health, Organization. Geneva: WHO; 2002.

13. Lima GRD, de Sales IRP, Filho MRDC, de Jesus NZT, Falcao HD, Barbosa-Filho JM, Cabral AGS, Souto AL, Tavares JF, Batista LM. Bioactivities of the genus Combretum (Combretacea): A Review. Molecules. 2012;17:9142-206.

14. Cock I.E. The medicinal properties and phytochemistry of plants of the genus Terminalia (Combretaceae). Inflammopharmacol 2015;23:203-229.

15. Masengu C, Zimba F, Mangoyi R, Mukanganyama S. Inhibitory Activity of Combretum zeyheri and its S9 Metabolites against Escherichia coli, Bacillus subtilis and Candida albicans. J Microbial Biochem Technol. 2014;6:228-35. doi:10.4172/1948-5948.1000149.

16. Mbwambo ZH, Mushi NF, Innocent E, Tewtrakul S. Antibacterial, anti-HIV-1 protease and cytotoxic activities of aqueous ethanolic extracts from Combretum adenogonium Steud, Ex A. Rich (Combretaceae). BMC Complement Altern Med. 2012;12:163.

17. Addullahi M, Saidu TB. Phytochemical determinations and antibacterial activities of the leaf extracts of Combretum molle and Gossypium Arboreum Bayero J Pure Appl Sci. 2011;4:132-6.

18. Amirkia V, Heinrich M. Alkaloids as drug-leads- A predictive structural and biodiversity-based analysis. Phytochem Lett. 2014;10:1874-3900.

19. Kittakoop P, Mhidol C, Ruchirawat S. Alkaloids as important scaffolds in therapeutic drugs for the treatments of cancer, tuberculosis, and smoking cessation. Curr Top Med Chem. 2014;14:239-52.

20. Liu X, Chen C, He W, Huang P, Liu M, Wang Q. Exploring anti-TB leads from natural products library originated from marine microbes and medicinal plants. Antonie van Leeuwenhoek. 2012;102:447-61.

21. Chaturvedi V, Dwivedi N, Tripathi RP, Sinha S. Evaluation of Mycobacterium smegmatis as a possible surrogate screen for selecting molecules active against multi-drug resistant Mycobacterium tuberculosis. J Gen Appl Microbiol. 2007:53:333-7.

22. Harbone AJ. Phytochemical Methods A Guide to Modern Techniques of Plant Analysis. Netherlands: Springer; 1988. XIV, 302.

23. Harbone AJ. Phytochemical methods: a guide to Modern Techniques of Plant Analysis. 2nd ed. London: Chapman and Hall Limited; 1973. p. 49-189.

24. Martini $\mathrm{N}$, Eloff JN. The preliminary isolation of several antibacterial compounds from Combretum erythrophyllum (Combretaceae). J Ethnopharmacol. 1998;62:255-63.

25. Berridge N. Tetrazolium dyes as tools in cell biology and new insights into their cellular reduction. Biotechnol Annu Rev. 2005;11:127-52.

26. Mortimer PGS, Piddock LJV. Comparison for the methods for measuring the accumulation of quinolones into Enterobacteriaceae, Pseudomonas aeruginosa and Staphylococcus aureus. J Antimicrob Chemother. 1991;28:639-53.

27. Oladosu P, Ibrahim K, Okolo P, Oladepo DK. Time-kill kinetics antibacterial study of Acacia nilotica. Afr J Microbiol. 2013;7:5248-52.
28. Kumar JK, Devi Prasad AG, Chaturvedi V. Phytochemical screening of five medicinal legumes and their evaluation for in vitro anti-tubercular activity. AYU. 2014;35:98-102.

29. Mann A, Ibrahim K, Oyewale AO, Amupitan JO, Fatope MO, Okogun Jl. Isolation and elucidation of three triterpenoids and its antimycobacterial activity of Terminalia avicennioides. Am J Org Chem. 2012;2:14-20.

30. Eloff JN, Masoko P. The diversity of antifungal compounds of six South African Terminalia species (Combretaceae) determined by bioautography. Afr J Biotechnol. 2005:4:1425-15.

31. Masoko P, Nxumalo M. Validation of antimycobacterial plants used by traditional healers in three districts of the Limpopo province (South Africa). Evid Based Complement Alternat Med. 2013;2013(586247):1-7.

32. Coulter ID, Willis EM. The rise and rise of complementary and alternative medicine: a sociological perspective. Med J Aust. 2004;180:587-89.

33. Maroyi A. An ethno-botanical survey of medicinal plants used by the people in Nhema communal area, Zimbabwe. J Ethnopharmacol. 2011;136:347-54.

34. Rogers CB, Verotta L, Chinyanga F, Millard M, Wolfender JL. Chemistry and biological properties of the African Comretaceae. University of Zimbabwe Publications: 1996;231-34.

35. Zuniga ES, Earl J, Parish T. The future for early-stage tuberculosis drug discovery. Future Microbiol. 2015;10:217-29.

36. Ramos DF, Leitao GG, Costa FN, Abeu L, Villarreal JV, Leitao SG, Fernandez SLS, da Silva PEA. Investigation of the antimycobacterial activity of 36 plant extracts from the Brazilian Atlantic Forest. Braz J Pharm Sci. 2008:44:669-74.

37. Ohene-Agyei T, Mowla R, Rahman T, Venter H. Phytochemicals increase the antibacterial activity by acting on a drug efflux pump. Microbiol Open. 2014;3:885-96.

38. Rodrigues L, Ramos J, Couto I, Amaral MV MV. Ethidium bromide transport across Mycobacterium smegmatis cell-wall: correlation with antibiotic resistance. BMC Microbiol. 2011;11:1471-2180.

39. Zhang I, Li X, Nikaido H. Efflux pump-mediated intrinsic drug resistant in Mycobacterium smegmatis. Antimicrob Agents Chemother. 2004;7:2415-23.

40. Titgemeyer F, Amon J, Parche S, Mahfound M, Bail J, Schlicht W, Rehm N, Hilmann D, Stephan J, Walter B, Burkovski A, Niederweis M. A genomic view of sugar transport in Mycobacterium smegmatis and Mycobacterium tuberculosis. J Bacteriol. 2007;189:5903-15.

41. Garvey MI, Piddock $\sqcup V$. The efflux pump inhibitor reserpine selects multidrugresistant Streptococcus pneumoniae strains that overexpress the ABC transporters PatA and PatB. Antimicrob Agents Chemother. 2008;52:1677-85.

42. Balganesh M, Dinesh N, Sharma S, Kuruppath S, Nair AV, Sharma U. Efflux pumps of Mycobacterium tuberculosis play a significant role in antituberculosis activity of potential drug candidates. Antimicrob Agents Chemother. 2012;10:2643-51.

43. Pandey AK, Kumar S. Perspective on Plant Products as Antimicrobials Agents: A Review. Pharmacologia. 2013;4:469-80.

44. Szumowski JD., Adams KN, Edelstein PH, and Ramakrishnan L. Antimicrobial efflux pumps and Mycobacterium tuberculosis drug tolerance: Evolutionary Considerations. Curr Top Microbiol Immunol. 2013. 374: 10.1007/82_2012_300

45. Li G, Zhang J, Guo Q, Jiang Y, Wei J, Zhao LL, Zhao X, Lu J, Wan K. Efflux pump gene expression in multidrug-resistant Mycobacterium tuberculosis clinical isolates. PLoS One. 2015;10(2):e0119013.

\section{Submit your next manuscript to BioMed Central and we will help you at every step:}

- We accept pre-submission inquiries

- Our selector tool helps you to find the most relevant journal

- We provide round the clock customer support

- Convenient online submission

- Thorough peer review

- Inclusion in PubMed and all major indexing services

- Maximum visibility for your research

Submit your manuscript at www.biomedcentral.com/submit 